\title{
Use of moist grain maize silage with or without cobs in weaned piglet feeding from 9 to $24 \mathrm{~kg}$
}

\author{
J. CASTAING *, R. COUDURE*, J. FEKETE ** \\ * A.G.P.M., 122, boulevard Tourasse, 64000 Pau \\ **:T.T.C.F., 8, avenue du Président-Wilson, 75116 Paris
}

Feeding value of grain maize silage with or without cobs in ad libitum teeding of weaned piglets was studied after two maize harvests (1982 and 1983).

Silages used were characterized by dry matter contents ranging from 595 to $670 \mathrm{~g} / \mathrm{kg}$. The cellulose Weende contents of silages with cobs (G.M.C.) ranged between 57 and $78 \mathrm{~g} / \mathrm{kg}$ DM. Silage lots were incorporated in replacement of dry grain maize into maizesoyabean diets on the basis of the dry matter content.

A total of 576 and 744 piglets respectively were used in the two trials. They were weaned at the mean age of 27 days. After an adaptation period of 11 days they were fed experimental diets based on dry grain maize or silages for 28 days. Diets including silage in the form of flour were offered in sufficient amounts, but an accumulation of feed was avoided in the feeders.

The cob-free grain maize silage, whatever its moisture, led to growth and feed conversion performances not significantly different from those of the control diet based on dry grain maize. Grain maize with cobs (G.M.C.) reduced the growth rates by 5.0 and 6.0 p. 100 in both trials as compared to the control diet. The increased feed conversion ratio observed was all the larger as the crude fibre was high.

\section{Determination of the feeding value of grain maize silage with cobs in restricted bacon pigs}

\author{
J. CASTAING *, R. COUDURE *, F. GROSJEAN ** \\ *A.G.P.M., 122, boulevard Tourasse, 64000 Pau \\ ** I.T.C.F., 8, avenue du Président-Wilson, 75116 Paris"
}

Two trials were made to compare the performances of pigs fed diets based on grain maize silage or on silage including $70 \%$ to $100 \%$ of the ear cob (Grain Maize Cob or G.M.C.) (harvest 1983).

In some treatments pigs received the same amount of dry matter per day with grain alone or with G.M.C., while in others they received higher levels of DM to reach the same performances as with the grain.

In the 1st trial, with crude fibre rich G.M.C. lots $(78 \mathrm{~g} / \mathrm{kg}$ DM for the whole ear without husks) the dietary supply was increased by $10 \mathrm{p}$. 100 to reach the same growth rate as with the cob free grain. Accordingly, the increase in the feed conversion ratio ranged from 9 to 11.6 p. 100 , respectively with 70 or 100 p. 100 cobs in the silage. In the second trial, G.M.C. « 90 » lots exhibited a lower crude fibre content $(67 \mathrm{~g} / \mathrm{kg} \mathrm{DM})$. The adjustment of the feed restriction led to growth rates similar to that of the control. The increase in the feed conversion ratio reached 8.4 p. 100 as compared to the control with maize lots including cobs whatever the level of feed restriction.

Comparison of trials made with different G.M.C. lots showed a linear relationship between the increase in the feed conversion ratio and the crude fibre content of the silages. 